\title{
Are young people with primary social anxiety disorder less likely to recover following generic CBT compared to young people with other primary anxiety disorders? A systematic review and meta-analysis
}

\author{
Rachel Evans ${ }^{1}$, David M. Clark ${ }^{2}$ and Eleanor Leigh ${ }^{2, *}$ (1) \\ ${ }^{1}$ Department of Psychology, IoPPN, King's College London, London, UK and ${ }^{2}$ Department of Experimental Psychology, \\ University of Oxford, Oxford, UK \\ *Corresponding author. Email: eleanor.leigh@psy.ox.ac.uk
}

(Received 18 March 2020; revised 24 July 2020; accepted 23 September 2020; first published online 10 December 2020)

\begin{abstract}
Background: Social anxiety disorder (SoAD) in youth is often treated with a generic form of cognitive behavioural therapy (CBT). Some studies have suggested that primary SoAD is associated with lower recovery rates following generic CBT compared with other anxiety disorders.

Aims: This systematic review and meta-analysis investigated recovery rates following generic CBT for youth with primary SoAD versus other primary anxiety disorders.

Method: Five databases (PsycINFO, Web of Science, PubMed, Embase, Medline) were searched for randomised controlled trials of generic CBT for child and/or adolescent anxiety.

Results: Ten trials met criteria for inclusion in the systematic review, six of which presented sufficient data for inclusion in the meta-analysis. Sixty-seven did not report data on recovery rates relative to primary diagnosis. While most individual studies included in the systematic review were not sufficiently powered to detect a difference in recovery rates between diagnoses, there was a pattern of lower recovery rates for youth with primary SoAD. Across the trials included in the meta-analysis, the post-CBT recovery rate from primary SoAD (35\%) was significantly lower than the recovery rate from other primary anxiety disorders (54\%).

Conclusions: Recovery from primary SoAD is significantly less likely than recovery from any other primary anxiety disorder following generic CBT in youth. This suggests a need for research to enhance the efficacy of CBT for youth SoAD.
\end{abstract}

Keywords: adolescents; anxiety; children; cognitive behavioural therapy; social anxiety disorder

\section{Introduction}

Social anxiety disorder (SoAD) is characterised by an intense fear of embarrassment or negative evaluation by others which causes significant distress and functional impairment. It is common, with a lifetime prevalence of $12 \%$ (Kessler et al., 2005). It has a median age of onset of 13 years (Kessler et al., 2005) and a stable, chronic presentation in both young people and into adulthood (Bruce et al., 2005). In young people, SoAD is associated with poor academic achievement (Van Ameringen et al., 2003) and peer victimization (Ranta et al., 2009). SoAD continues to be associated with functional impairments across work and social domains in adulthood (Aderka et al., 2012). Moreover, adolescent SoAD is associated with development of subsequent depression (Stein et al., 2001), which itself is predictive of a range of a range of functional impairments (McKnight and Kashdan, 2009).

(C) British Association for Behavioural and Cognitive Psychotherapies 2020. This is an Open Access article, distributed under the terms of the Creative Commons Attribution licence (http://creativecommons.org/licenses/by/4.0/), which permits unrestricted re-use, distribution, and reproduction in any medium, provided the original work is properly cited. 
For the treatment of SoAD in adults, the National Institute of Health and Care Excellence (NICE, 2013) recommend individual cognitive behavioural therapy (CBT) based on a disorder-specific model (i.e. Clark and Wells, 1995; Rapee and Heimberg, 1997). It is unusual for psychological interventions to show superior outcomes to other active treatment conditions. However, CBT for SoAD following the Clark and Wells model has been shown to be more effective than exposure therapy (Clark et al., 2006), group CBT (Mörtberg et al., 2007; Stangier et al., 2003) interpersonal psychotherapy (Stangier et al., 2011), psychodynamic psychotherapy (Leichsenring et al., 2013) and medication (Clark et al., 2003; Mörtberg et al., 2007; Nordahl et al., 2016; Yoshinaga et al., 2016).

A recent review identified empirical studies supporting the applicability of the Clark and Wells (1995) model to adolescent social anxiety (Leigh and Clark, 2018) and there is emerging evidence of the effectiveness of cognitive therapy for adolescent SoAD based on this model (Ingul et al., 2014; Leigh and Clark, 2016). This approach includes an individualised formulation based on a disorder-specific model of SoAD (e.g. Clark and Wells, 1995) followed by a range of techniques aimed at targeting maintenance factors identified in this model, for example using tailored behavioural experiments, attention training and memory rescripting. In contrast, generic CBT typically involves components such as psycho-education, graded exposure, problem solving and coping strategies which are not included in cognitive therapy (Spence et al., 2017). However, generally there has been a lack of research into disorder-specific interventions for child and adolescent SoAD, as reflected in the NICE guidelines which do not specifically recommend disorder-specific CBT for SoAD in youth (NICE, 2013). Indeed, as highlighted by Creswell et al. (2014), there has historically been a lack of research investigating disorder-specific models and therefore treatments across the range of anxiety disorders in youth. In a recent review, Creswell et al. (2020) have emphasised the need to move away from the historical 'one-size-fits-all' approach to disorder-specific CBT for child and adolescent anxiety disorders.

The efficacy of generic CBT for the treatment of anxiety disorders in young people has been supported by several reviews, with odds ratio for recovery of 3.3-7.85 following CBT compared with waitlist control (Cartwright-Hatton et al., 2004; James et al., 2013). However, several authors have suggested that youth with SoAD may experience poorer treatment outcomes than those with other anxiety disorders. In an analysis of predictors of outcome from a large randomised controlled trial (RCT), Ginsburg et al. (2011) found that young people with SoAD anywhere in their diagnostic profile were less likely to be in remission following CBT, compared with those without SoAD: remission was observed in only $41 \%$ of those with SoAD, compared with $72 \%$ of those without. Hudson, Keers et al. (2015) integrated data from 1519 children who received a course of $\mathrm{CBT}$ for anxiety in RCTs across 11 international sites, to reveal that youth with primary or secondary SoAD experienced significantly lower rates of recovery from their primary diagnoses following CBT, compared with those without SoAD. A similar pattern has been found at long-term follow-up: Kerns et al. (2013) reported that presence of SoAD anywhere in the profile was predictive of poorer diagnostic outcomes 7.4 years post-CBT as delivered in an RCT.

Whilst some individual studies have demonstrated poorer outcomes for youth with SoAD compared with those with other anxiety disorders, findings to date from reviews have been mixed. In a review investigating pre-treatment predictors of outcome following psychological treatments for child and adolescent anxiety, Knight et al. (2014) concluded 'emerging evidence' to suggest that primary SoAD predicted poorer outcome, whereas generalised anxiety disorder predicted superior outcome. However, in a review of child and family characteristics as predictors of outcome from cognitive therapy, Lundkvist-Houndoumadi et al. (2014) concluded there was insufficient evidence to suggest that any primary diagnosis was predictive of treatment outcome. More recently, Walczak et al. (2018) conducted a review investigating whether co-morbidity predicted outcomes following CBT for child anxiety 
disorders. This review concluded that SoAD may be associated with poorer outcomes following CBT, although it did not specifically focus on recovery outcomes for those with primary SoAD and did not report a quantitative synthesis (meta-analysis of results). Therefore, whilst this provides further evidence to suggest a relationship between SoAD and recovery rates, it does not provide a clear answer regarding outcomes for young people with primary SoAD compared with other anxiety disorders.

Given the prevalence of SoAD and associated functional impairments in young people, and suggestions from several authors that SoAD may be less responsive to generic CBT than other anxiety disorders, this issue clearly merits further investigation. Although previous reviews have attempted to identify factors which predict outcomes from CBT, the current review is the first to specifically investigate the role of primary SoAD in recovery from generic CBT. If it is the case that young people with primary SoAD experience significantly poorer outcomes following generic CBT, this would necessitate further research into disorder-specific interventions for social anxiety in young people. Such a finding would also have implications for clinical services, as it would suggest that young people with primary SoAD may require alternative treatment such as disorder-specific CBT (e.g. Ingul et al., 2014; Leigh and Clark, 2016).

The efficacy of disorder-specific CBT for SoAD, generalised anxiety disorder (GAD), separation anxiety disorder (SAD) and specific phobia (SP) has recently been considered in a systematic review conducted by Oldham-Cooper and Loades (2017). This review focused on one generic format of CBT (individual CBT following the 'Coping Cat' manual; Kendall, 1994) compared with disorder-specific psychological treatments. The review concluded that there was no evidence to favour disorder-specific over generic CBT for anxiety disorders. However, Oldham-Cooper and Loades only included one trial of disorder-specific CBT for SoAD, clearly limiting the strength of findings related to this diagnosis. A recent comparison of online generic versus disorder-specific CBT for SoAD (Spence et al., 2017) found that whilst the disorder-specific intervention was associated with greater reductions in SoAD maintenance processes and improvements in functioning, there was no significant difference in recovery outcomes at 12 weeks or at 6 months follow-up. However, the sample size of this trial did not provide sufficient statistical power to detect a difference between these two active treatment conditions. Moreover, it is important to clarify that a lack of evidence of the superiority of disorder-specific CBT does not necessarily demonstrate equivalence of outcomes for young people with SoAD compared with other anxiety disorders. It is quite possible for it to be true that current disorder-specific models of CBT have not demonstrated superiority over generic treatments for SoAD, and that young people with SoAD have poorer outcomes from generic CBT.

It is clear from the discussed literature that SoAD is a common difficulty in young people with disabling implications. The suggestion from several trials that young people with SoAD experience poorer outcomes from CBT, coupled with the lack of overall clarity from reviews of the topic, necessitate further investigation. Better understanding of this issue is crucial, as this can inform the development and implementation of better psychological therapies for this common disorder in young people. The present review therefore set out to investigate diagnostic outcomes following generic CBT for young people with primary SoAD in comparison with those with other primary anxiety disorders. Specifically, we set out to investigate remission from primary anxiety diagnosis (defined as no longer reporting symptoms in the clinical range on either young person or parent report on diagnostic assessment tools), at post-treatment, in children and/or adolescents with an average age of 7-18 years. In contrast to the Oldham-Cooper and Loades (2017) review, the present review included any form of CBT (i.e. following a range of manualised approaches and group/ individual formats). This approach was taken in order to maximise generalisability of conclusions, both in terms of numbers of trials to be included and to reflect the varied ways in which $\mathrm{CBT}$ is delivered to young people with SoAD in routine clinical settings. The present 
study set out to complete a meta-analysis as well as systematic review, to overcome the common issue of insufficient power within studies to compare outcomes for participants with different primary anxiety diagnoses.

\section{Method}

\section{Protocol and registration}

The protocol for the review is available online at: https:/www.crd.york.ac.uk (ID: CRD42019122593). The review followed PRISMA (2009) guidelines (Moher et al., 2009). The PRISMA checklist can be found in Appendix A in Supplementary material.

\section{Eligibility criteria}

Inclusion and exclusion criteria were pre-determined and are available at: https://www.crd.york. ac.uk (ID: CRD42019122593). The inclusion criteria were: (i) participants aged 7-18 years, or mean age of 8-17 years, (ii) RCTs of any type of CBT for anxiety disorders (e.g. group/ individual format, with/without parental involvement), (iii) includes validated diagnostic assessment at pre- and post-intervention (e.g. ADIS-IV-C/P; Silverman and Albano, 1996), (iv) includes participants with primary SoAD and other anxiety disorder(s) [generalised anxiety disorder, separation anxiety disorder, panic disorder (PD) with/without agoraphobia (AP), AP without PD, SP, anxiety disorder not otherwise specified (ADNOS)], (v) reports recovery outcomes separately for young people with each of the included primary anxiety diagnoses, or an analysis of the moderating effect of primary social anxiety on outcome, (vi) published in a peer-reviewed journal, (vii), written in English, and (viii) published 1990-2019. The exclusion criteria were: (i) a focus on anxiety in participants with diagnosed autism spectrum disorder (ASD), attention deficit hyperactivity disorder, or intellectual disabilities, (ii) sample size $<10$, (iii) reports replicated data only, and (iv) in line with Oldham-Cooper and Loades (2017), young people with a diagnosis of obsessive compulsive disorder (OCD), post-traumatic stress disorder (PTSD) or selective mutism were excluded. OCD and PTSD were excluded because they are not defined as anxiety disorders within DSM-5. Young people with a diagnosis of selective mutism were excluded because standard CBT approaches have required adaptation for this group (Hudson et al., 2001).

\section{Information sources}

Five databases (PsycINFO, Web of Science, PubMed, Embase, Medline) were searched for articles within the date range of 1990-2019. Hand forward and back searching was conducted by reviewing the reference lists of existing relevant reviews (Cartwright-Hatton et al., 2004; James et al., 2013; Knight et al., 2014; Lundkvist-Houndoumadi et al., 2014; Oldham-Cooper and Loades, 2017; Reynolds et al., 2012).

\section{Search}

PsycINFO, Web of Science and PubMed were searched on 21 January 2019, and Embase and Medline were searched on 11 March 2019. The search of all five databases was re-run on 21 October 2019, to account for any further relevant studies published during the main data extraction phase. The search terms were designed to retrieve all research studies that had evaluated CBT for anxiety disorders in children and adolescents. These were searched in abstracts and titles of all five databases with limits regarding year range (1990-current), language (English) and source (journal articles only). Although studies focusing on people with ASD or intellectual disabilities were excluded from the current review, the research team opted to manually remove these studies rather than state these in the search terms. 
This approach was used to minimise the risk of the electronic search erroneously excluding papers which met the inclusion criteria. For an example full electronic search, see Appendix B in Supplementary material. The search terms used are outlined below:

\section{Youth OR adolescent OR adolescence OR Child OR CAMHS OR Teenage OR CAMS OR Young people OR Pediatric OR Paediatric}

$A N D$

Anxiety OR Anxiety disorder OR social anxiety disorder OR social phobia OR social anxiety OR Panic disorder OR Specific phobia OR Agoraphobia OR Separation anxiety disorder OR Generalised anxiety disorder OR Generalized anxiety disorder

\section{$A N D$}

Cognitive behavioural therapy OR Cognitive behavioral therapy OR Cognitive behaviour therapy OR Cognitive behavior therapy OR Cognitive therapy OR CBT

\section{Study selection}

Studies were initially screened based on title, and studies that clearly did not meet the inclusion criteria were excluded. This process was completed cautiously, and any studies which may have met inclusion criteria were reviewed further based on abstract at the next stage. Examples of papers that could clearly be excluded at title stage were those focused on anxiety in people with diagnosed ASD, those evaluating psychological therapies for anxiety disorders in adults only, and single case studies or other clearly non-RCT designs. Abstracts of remaining studies were then reviewed against the inclusion criteria. Again, if it was unclear from the abstract whether the study met inclusion criteria, it was carried forward to the full text review stage. The final stage was to review the full texts of all studies included based on abstract. The screening and selection process was completed by one researcher (R.E.) and in cases of ambiguity regarding whether studies met inclusion criteria, this was discussed and agreed with a second researcher (E.L.). Studies were included in the meta-analytic synthesis if they provided data on the number of participants who recovered from primary social anxiety and from other primary anxiety diagnoses.

\section{Data collection process}

Data were extracted from each of the papers by two independent researchers (R.E. and M.T.). Prior to data extraction, the research team agreed on which data would be sought for extraction. A spreadsheet was developed by the research team to enable the standardised collection of all relevant data from each paper where available. For trials in which the manuscript did not provide sufficient data for inclusion in meta-analytic synthesis $(n=8)$, authors were contacted to request this information. The required data for inclusion in metaanalysis was provided by four of these eight authors.

\section{Data extraction variables}

Data on the following variables were extracted: participant demographics (age, gender, ethnicity, inclusion/exclusion criteria, number allocated to each condition), intervention characteristics (CBT manual, duration and format of CBT and control group, drop-out rates) and diagnostic outcomes following CBT (diagnostic tool used, timing of assessments, number or percentage of participants who recovered from each anxiety disorder, and any analysis/reporting of 
relationship between primary diagnosis and recovery rates). All diagnostic outcome data were collected at the first assessment following completion of CBT only.

\section{Risk of bias in individual studies}

Risk of bias in individual studies was assessed using the Cochrane Collaboration Risk of Bias Tool (Higgins et al., 2011). Each study was assessed against each of the six criteria of the tool by two independent researchers (R.E. and G.S.). The researchers then met to discuss ratings. Agreement on ratings was high, with the two researchers agreeing on $96 \%$ of ratings prior to discussion. The remaining ratings where there were discrepancies between the researchers were resolved through discussion between the researchers (R.E., G.S. and E.L.).

\section{Data analysis (meta-analysis)}

Analyses for quantitative synthesis were conducted using RevMan software (version 5.3). The data included in this analysis were the number of participants who recovered from primary SoAD, the total number with primary SoAD, and equivalent numbers for all other primary anxiety disorders pooled. In the six trials included in the meta-analysis, the single most severe and impairing diagnosis based on youth or parent report was assigned as the primary diagnosis in accordance with ADIS-IV-C/P guidelines. Recovery from primary diagnosis is defined as being below ADIS-IV-C/P clinical severity thresholds for primary diagnosis based on both youth and parent report at post-treatment. A fixed effects model was used, as heterogeneity was acceptable $\left(I^{2}=0 \%\right)$. Recovery outcomes (number recovered from primary SoAD versus other primary anxiety disorders) were compared using odds ratio.

\section{Risk of bias across studies (meta-analysis)}

Risk of bias across studies (publication bias) was examined using a funnel plot.

\section{Results}

\section{Study selection}

After 956 titles were removed based on title, this left 479 to review based on abstract. At the full text stage, 130 texts were reviewed. Ten texts met criteria for inclusion in the review. Six papers provided sufficient data for inclusion in the meta-analytic synthesis, either in the original paper $(n=2)$ or in response to requests made to the author $(n=4)$. These stages, and reasons for exclusion, are outlined in Fig. 1.

\section{Study characteristics}

Ten published articles were included in the review. These RCTs evaluated a range of formats of CBT, including three of individual CBT (Barrett et al., 1996; Silk et al., 2018; Suveg et al., 2018), two of group CBT (Arendt et al., 2016; Shortt et al., 2001), two of individual or group CBT (Villabo et al., 2018; Wergeland et al., 2014; Wergeland et al., 2016), two of parent-delivered CBT (Creswell et al., 2017; Thirlwall et al., 2013; Thirlwall et al., 2017), and one of internetdelivered CBT (Stjerneklar et al., 2019). Sessions varied in length from 20 min telephone calls (+30 min online sessions) in Stjerneklar et al. (2019) to 2 hours (Arendt et al., 2016), with an average session length of $59 \mathrm{~min}(S D=33.71)$ across the seven studies which reported this information. Children and adolescents receiving CBT ranged in age from 5 to 17 years of age $($ mean $=10.50, S D=1.78)$. Further details of the trials are shown in Table 1. 

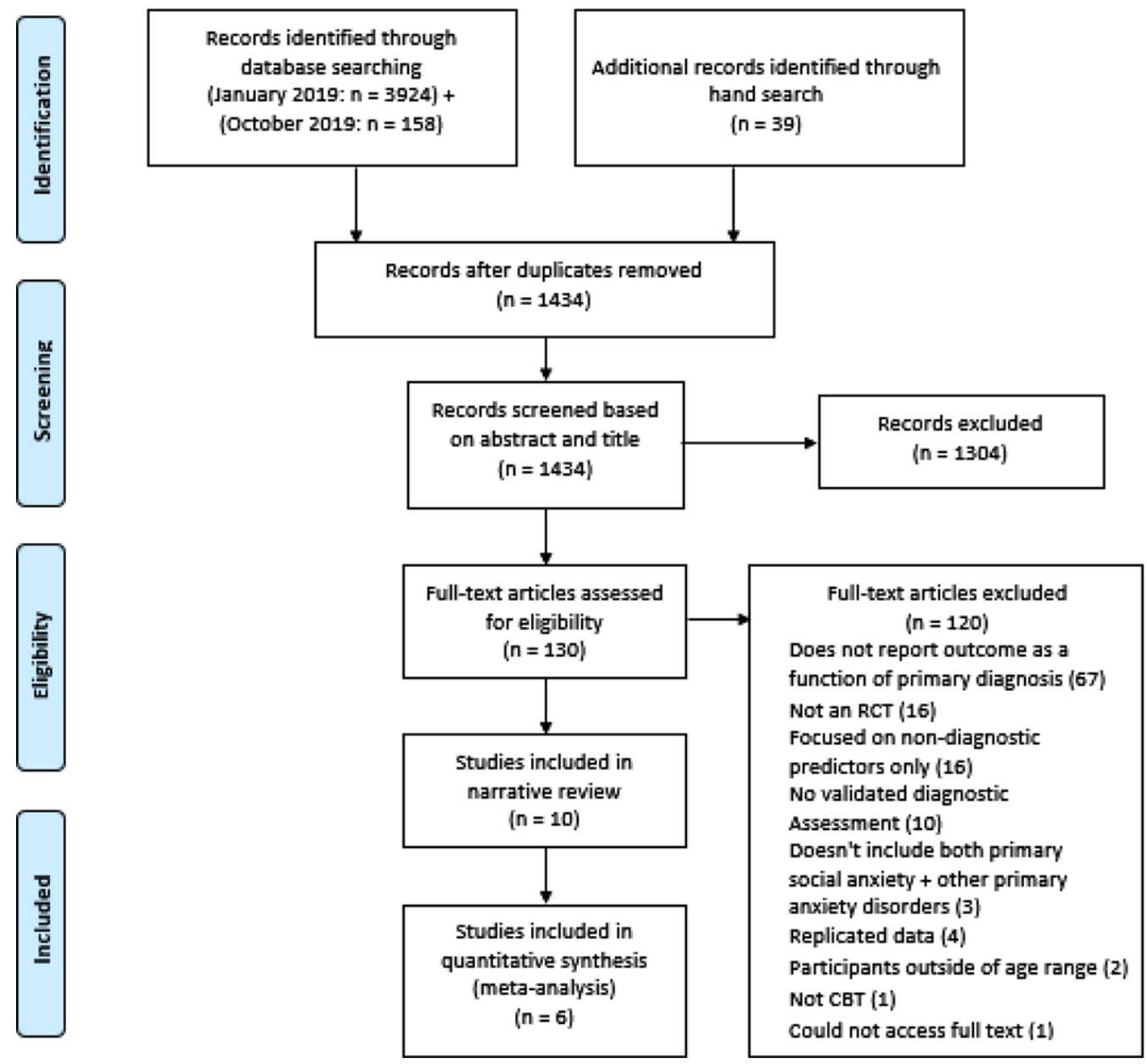

Figure 1. PRISMA flow diagram.

\section{Risk of bias within studies}

Investigation into risk of bias within studies revealed that across five of the six domains, the majority of trials showed low risk of bias. However, all but one trial had a high risk of bias related to participant blinding to treatment condition. This is a common feature of evaluations of CBT, as when comparing CBT with a control condition (e.g. wait list or treatment as usual), it is not possible to prevent participants from knowing which condition they are in. Indeed, it has been suggested in a previous review that this criterion should not be assessed for psychotherapy trials, due to the nature of their design (Reynolds et al., 2012). Additionally, two trials (Stjerneklar et al., 2019; Wergeland et al., 2014; Wergeland et al., 2016) had a high risk of bias in outcome assessment, as assessors were not blind to treatment condition at post-treatment. A summary of the risks of bias assessed in the papers is shown in Fig. 2.

\section{Management of missing data}

In eight of the trials, authors reported results based on intention-to-treat principles (with pre-treatment data carried forward in cases of missing data at post-treatment). Two trials 
Table 1. Characteristics of full texts included in review

\begin{tabular}{|c|c|c|c|c|c|c|c|}
\hline Author/year & Country & $\begin{array}{c}\text { Total } \\
\text { sample } \\
\text { size }\end{array}$ & $\begin{array}{l}\text { Age } \\
\text { range }\end{array}$ & $\begin{array}{c}\% \\
\text { female }\end{array}$ & $\begin{array}{l}\text { Primary anxiety } \\
\text { diagnoses included }\end{array}$ & CBT condition(s) & Diagnostic outcome measure \\
\hline $\begin{array}{l}\text { Barrett et al. } \\
\quad \text { (1996) }\end{array}$ & Australia & 79 & $7-14$ & $43 \%$ & SoAD, SAD, OAD & $\begin{array}{l}12 \text { sessions of individual CBT (Coping Cat; Kendall, } \\
\text { 1994) }\end{array}$ & $\begin{array}{l}\text { Anxiety Disorders Interview Schedule for } \\
\text { DSM-III (ADIS-III; Silverman and Nelles, } \\
\text { 1988) }\end{array}$ \\
\hline $\begin{array}{l}\text { Shortt et al. } \\
\text { (2001) }\end{array}$ & Australia & 71 & $6-10$ & $59 \%$ & SoAD, SAD, GAD & $\begin{array}{l}12 \text { sessions of group CBT (Friends programme; } \\
\text { Barrett, Lowry-Webster \& Turner, 2000a-f) }\end{array}$ & $\begin{array}{l}\text { Diagnostic Interview Schedule for Child, } \\
\text { Adolescents and Parents (DISCAP; } \\
\text { Holland and Dadds, 1995) }\end{array}$ \\
\hline $\begin{array}{l}\text { Thirlwall et al. } \\
\qquad(2013,2017)^{\star}\end{array}$ & UK & 194 & $7-12$ & $48 \%$ & $\begin{array}{l}\text { SoAD, SAD, GAD, SP, } \\
\text { PD without AP, PD } \\
\text { with AP, AP }\end{array}$ & $\begin{array}{l}\text { 4-8 sessions of individual guided parent-delivered } \\
\text { CBT (Willetts et al., 2016) }\end{array}$ & ADIS-IV-C/P \\
\hline $\begin{array}{l}\text { Wergeland et al. } \\
\qquad(2014,2016)^{*}\end{array}$ & Norway & 182 & $8-15$ & $53 \%$ & SoAD, SAD, GAD & $\begin{array}{l}10 \text { sessions of individual or group CBT (Friends } \\
\text { programme; Barrett, 2004) }\end{array}$ & ADIS-IV-C/P \\
\hline $\begin{array}{l}\text { Arendt et al. } \\
(2016)^{\star}\end{array}$ & Denmark & 109 & $7-16$ & $57 \%$ & $\begin{array}{l}\text { SoAD, SAD, GAD, SP, } \\
\text { PD with AP, AP }\end{array}$ & $\begin{array}{l}10 \text { sessions of group CBT (Cool Kids; Rapee et al., } \\
\text { 2006) }\end{array}$ & ADIS-IV-C/P \\
\hline $\begin{array}{l}\text { Creswell et al. } \\
\qquad(2017)^{\star}\end{array}$ & UK & 136 & $5-12$ & $53 \%$ & $\begin{array}{l}\text { SoAD, SAD, GAD, SP, } \\
\text { PD without AP, PD } \\
\text { with AP, ADNOS }\end{array}$ & $\begin{array}{l}8 \text { sessions of individual guided parent-delivered } \\
\text { CBT (Willetts et al., 2016) }\end{array}$ & ADIS-IV-C/P \\
\hline $\begin{array}{l}\text { Villabo et al. } \\
\qquad(2018)^{*}\end{array}$ & Norway & 165 & $7-13$ & $46 \%$ & SoAD, SAD, GAD & $\begin{array}{l}14 \text { sessions of individual or group CBT (Coping } \\
\text { Cat; Kendall and Martinsen, 2008; Kendall et al., } \\
\text { 2006) }\end{array}$ & ADIS-IV-C/P \\
\hline $\begin{array}{l}\text { Suveg et al. } \\
\text { (2018) }\end{array}$ & USA & 92 & $7-12$ & $42 \%$ & SoAD, SAD, GAD & $\begin{array}{l}10 \text { sessions of individual CBT [Coping Cat; Kendall, } \\
\text { 1994; or Suveg and Kendall (unpublished } \\
\text { manual)] }\end{array}$ & ADIS-IV-C/P \\
\hline Silk et al. (2018) & USA & 133 & $9-14$ & $56 \%$ & SoAD, SAD, GAD & $\begin{array}{l}16 \text { sessions of individual CBT (Coping Cat; Kendall } \\
\text { and Hedtke, 2006a,b) }\end{array}$ & ADIS-IV-C/P \\
\hline $\begin{array}{l}\text { Stjerneklar et al. } \\
(2019)^{\star}\end{array}$ & Denmark & 70 & $13-17$ & $79 \%$ & $\begin{array}{l}\text { SoAD, SAD, GAD, SP, } \\
\text { PD without AP, PD } \\
\text { with AP, AP, }\end{array}$ & $\begin{array}{l}14 \text { weeks of weekly therapist phone calls + } \\
\text { internet-based CBT (ICBT; Lyneham et al., 2014) }\end{array}$ & ADIS-IV-C/P \\
\hline
\end{tabular}

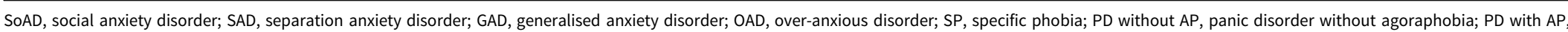
panic disorder with agoraphobia; AP, agoraphobia without panic disorder; ADNOS, anxiety disorder not otherwise specified. *Included in meta-analysis. 


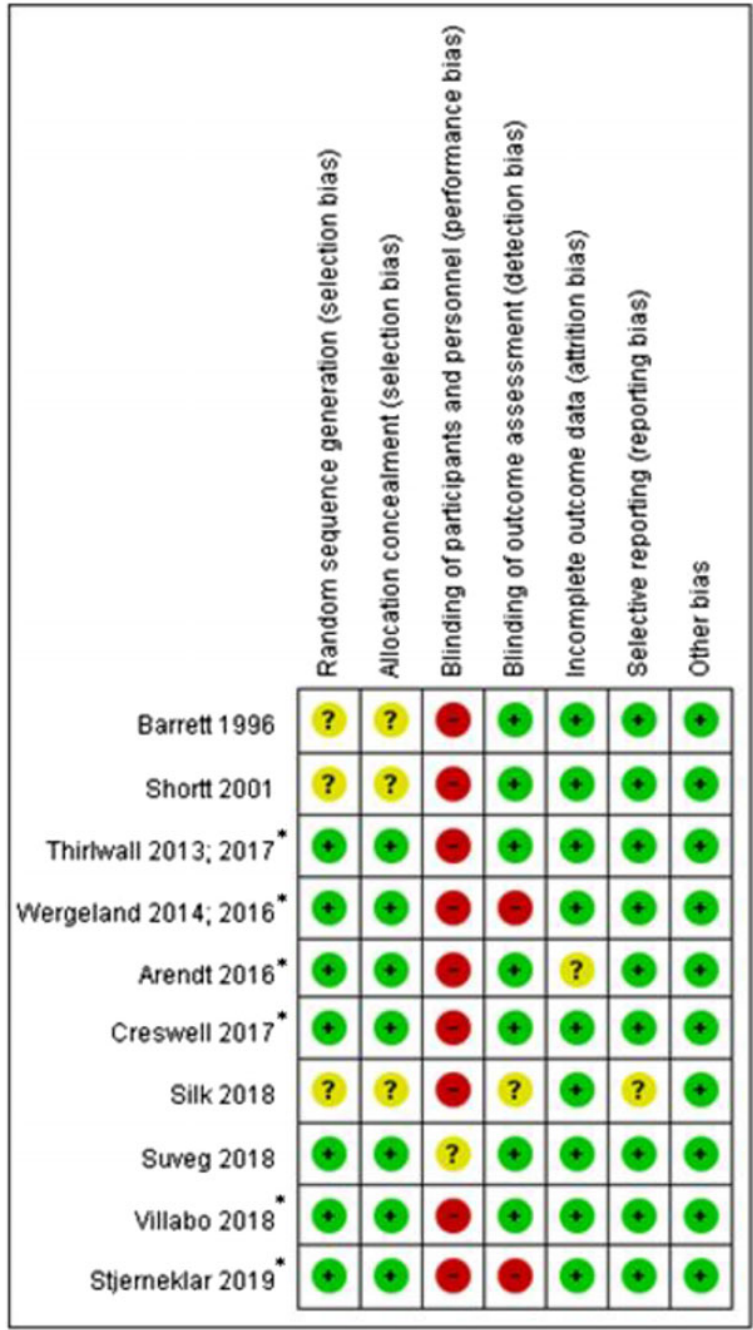

Figure 2. Risk of bias summary for each paper, according to Higgins et al. (2011) criteria. ${ }^{*}$ Included in meta-analysis.

(Shortt et al., 2001; Thirlwall et al., 2013; Thirlwall et al., 2017) reported sensitivity analysis which revealed no significant difference in outcomes when missing data were excluded compared with intention-to-treat analysis, and so opted to report results only for young people with available data at post-treatment.

\section{Narrative review of individual studies}

The trials used a range of formats and statistical approaches to present results related to recovery following CBT for young people with different primary anxiety diagnoses. As shown in Table 2, the proportion of young people who recovered from primary SoAD was lower than the proportion recovered from other primary anxiety disorders in seven of the eight trials which presented these data. The only trial which found greater recovery rates for youth with primary SoAD (Creswell et al., 2017) was based on a very small sample $(n=6)$ with this primary diagnosis. Furthermore, all results from individual studies regarding the proportion of young people who recovered must be interpreted with caution as the individual studies did not have sufficient statistical power to test the significance of this difference. 
Table 2. Post-CBT diagnostic outcomes reported in the included texts

\begin{tabular}{|c|c|c|c|c|}
\hline Author/year & $\begin{array}{l}\text { Sample size on whom } \\
\text { CBT recovery outcomes } \\
\text { are based }^{1}\end{array}$ & $\begin{array}{l}\text { \% recovered from } \\
\text { primary SoAD } \\
\text { post-CBT }\end{array}$ & $\begin{array}{l}\% \text { recovered from other } \\
\text { primary anxiety disorders } \\
\text { post-CBT }\end{array}$ & $\begin{array}{l}\text { Authors' conclusions regarding association between primary diagnosis and } \\
\text { likelihood of recovery }\end{array}$ \\
\hline $\begin{array}{l}\text { Barrett et al. } \\
\quad(1996)\end{array}$ & 53 & $62 \%$ & $73 \%$ & No significant association between primary diagnosis and recovery rates ${ }^{3}$ \\
\hline $\begin{array}{l}\text { Shortt et al. } \\
\quad(2001)\end{array}$ & 48 & $56 \%$ & $72 \%$ & No significant association between primary diagnosis and recovery rates ${ }^{3}$ \\
\hline $\begin{array}{l}\text { Wergeland et al. } \\
\qquad(2014,2016)^{*}\end{array}$ & 179 & $27 \%$ & $42 \%$ & $\begin{array}{l}\text { A primary SoAD or SAD diagnosis, compared with primary } G A D \text {, significantly } \\
\text { reduced the odds of recovery post-CBT }\end{array}$ \\
\hline $\begin{array}{l}\text { Arendt et al. } \\
(2016)^{*}\end{array}$ & 101 & $29 \%$ & $65 \%$ & $\begin{array}{l}\text { Participants with primary SoAD were significantly less likely to be recovered at } \\
\text { post-treatment than those with any other primary anxiety diagnosis }\end{array}$ \\
\hline $\begin{array}{l}\text { Creswell et al. } \\
(2017)^{\star}\end{array}$ & $62^{2}$ & $50 \%$ & $45 \%$ & $\begin{array}{l}\text { Significant association between primary GAD and post-treatment severity of } \\
\text { primary diagnosis (reflecting greater improvement in severity of primary GAD } \\
\text { compared with other primary anxiety diagnoses) }\end{array}$ \\
\hline $\begin{array}{l}\text { Villabo et al. } \\
\qquad(2018)^{*}\end{array}$ & 165 & $55 \%$ & $63 \%$ & Not reported \\
\hline $\begin{array}{l}\text { Suveg et al. } \\
\text { (2018) }\end{array}$ & 92 & Not reported & Not reported & $\begin{array}{l}\text { No significant difference in recovery rates by primary diagnoses, although co- } \\
\text { morbid primary diagnoses were used, and co-morbidity was high }(>90 \%) 3\end{array}$ \\
\hline Silk et al. (2018) & 90 & Not reported & Not reported & $\begin{array}{l}\text { Pre-treatment diagnosis did not significantly predict or moderate recovery } \\
\text { post-CBT }\end{array}$ \\
\hline $\begin{array}{l}\text { Thirlwall et al. } \\
\qquad(2013,2017)^{\star}\end{array}$ & 96 & $38 \%$ & $49 \%$ & $\begin{array}{l}\text { Participants with primary GAD were significantly more likely to have recovered } \\
\text { from their primary diagnosis at post-treatment than those with all other } \\
\text { primary anxiety disorders }\end{array}$ \\
\hline $\begin{array}{l}\text { Stjerneklar et al. } \\
(2019)^{\star}\end{array}$ & 32 & $21 \%$ & $50 \%$ & Not reported \\
\hline
\end{tabular}

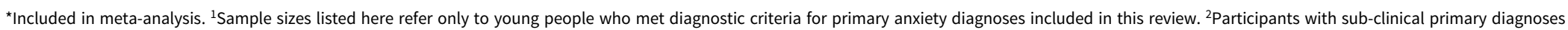
$(n=4)$ excluded. ${ }^{3}$ Statistical power to detect a between-group effect not reported. 
Eight trials reported additional analyses of the association between primary diagnosis and recovery post-CBT. Of these, four (Barrett et al., 1996; Shortt et al., 2001; Silk et al., 2018; Suveg et al., 2018) reported no significant association between primary diagnosis and recovery rates following CBT. However, none of these trials reported whether there was adequate statistical power to detect a significant difference.

Two trials (Thirlwall et al., 2013; Thirlwall et al., 2017; Wergeland et al., 2014; Wergeland et al., 2016) concluded that a diagnosis of primary GAD was associated with significantly higher rates of recovery at post-treatment compared with other primary anxiety disorders (including SoAD). Additionally, Creswell et al. (2017) reported greater change in severity of primary diagnosis at post-treatment for young people with primary GAD compared with other primary diagnoses. One trial (Arendt et al., 2016) concluded that recovery from primary diagnosis was significantly less likely for participants with primary SoAD compared with all other primary anxiety diagnoses. Arendt and colleagues also identified that youth with primary SoAD were more likely be older than youth with $\mathrm{GAD}$ or $\mathrm{SAD}$ and were more likely to report a co-morbid mood disorder compared with youth with any other primary anxiety diagnosis. However, the significant association between primary SoAD and lower recovery rates postCBT remained significant after controlling for age and mood. Further information on these findings is shown in Table 2.

\section{Quantitative synthesis: meta-analysis}

In order to further examine the association between primary diagnosis and recovery following CBT, a meta-analysis was conducted on the number of young people who recovered from primary SoAD versus other primary anxiety disorders at post-CBT, relative to the number who had these diagnoses at pre-CBT. These data were available for six of the 10 studies included in the systematic review (Arendt et al., 2016; Creswell et al., 2017; Stjerneklar et al., 2019; Thirlwall et al., 2013; Thirlwall et al., 2017; Villabo et al., 2018; Wergeland et al., 2014; Wergeland et al., 2016). These papers presented data on 635 children and adolescents allocated to CBT conditions. Of these, 180 had primary SoAD and 455 had other primary anxiety disorders $(\mathrm{SAD}=195, \mathrm{GAD}=180, \mathrm{SP}=56, \mathrm{PD}$ without $\mathrm{AP}=6, \mathrm{PD}$ with $\mathrm{AP}=4$, $\mathrm{AP}=12, \mathrm{ADNOS}=2)$. As heterogeneity was low $\left(I^{2}=0 \%\right)$, a fixed-effects model was used. The meta-analysis revealed that the likelihood of recovery from primary diagnosis was significantly lower for participants with primary SoAD than those with other primary anxiety disorders, OR $=.52(95 \% \mathrm{CI} . .36, .76), z=3.41, p<.001$. These results are shown in Fig. 3. As a sensitivity analysis, this meta-analysis was repeated using a random-effects model. This revealed a highly similar pattern of results to the fixed-effects model.

\section{Risk of bias across studies: meta-analysis}

A funnel plot was examined of the six studies included in the meta-analysis. This did not indicate evidence of publication bias (see Appendix C in Supplementary material).

\section{Discussion}

This review investigated the question of whether young people with primary SoAD were less likely to recover following generic CBT compared with those with other primary anxiety disorders. In the systematic review, the proportion of young people who recovered from primary SoAD was lower than the proportion who recovered from any other primary anxiety disorders in seven of the eight trials which presented these data. However, these trials did not individually have sufficient statistical power to test for the significance of these differences. In terms of the trial authors' own analysis of the relationship between primary diagnosis and recovery, four trials 


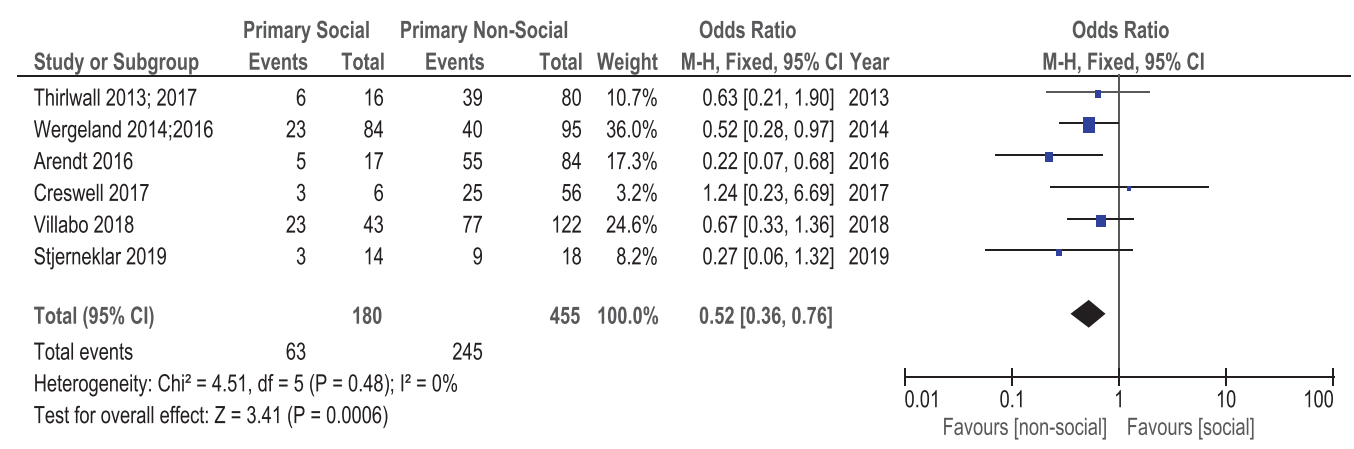

Figure 3. Forest plot showing recovery from primary SoAD vs non-social primary anxiety disorders. Data reported for Villabo et al. (2018) are averaged across individual and group CBT conditions.

(Barrett et al., 1996; Shortt et al., 2001; Silk et al., 2018; Suveg et al., 2018) reported no significant association. However, again this must be understood in the context that these trials individually did not have sufficient statistical power to detect such a difference. Nonetheless, three trials concluded that primary GAD was associated with superior diagnostic outcomes post-CBT, and one trial specifically concluded that primary SoAD was associated with poorer recovery rates following CBT compared with other anxiety disorders.

The results from the quantitative synthesis were clearer. When combining the results of six trials which presented sufficient data for inclusion (Arendt et al., 2016; Creswell et al., 2017; Stjerneklar et al., 2019; Thirlwall et al., 2013; Thirlwall et al., 2017; Villabo et al., 2018; Wergeland et al., 2014; Wergeland et al., 2016), this revealed that 35\% of young people with primary social anxiety recovered from this diagnosis following generic CBT, compared with $54 \%$ of young people with other primary anxiety disorders. The odds ratio statistic revealed that young people with primary SoAD were $48 \%$ less likely to have recovered from this diagnosis post-CBT compared with those with any other primary anxiety disorder. This difference was highly statistically significant. These results complement previous findings that social anxiety anywhere in the diagnostic profile is associated with poorer outcomes following generic CBT (Ginsburg et al., 2011; Hudson, Keers et al., 2015; Kerns et al. 2013). This has also been suggested in a recent review investigating the role of co-morbidity in outcome following CBT (Walczak et al., 2018). The present review is the first to demonstrate that primary social anxiety specifically is associated with lower recovery rates following CBT.

This review also builds on the conclusion of the 2014 review by Knight and colleagues (2014) which found emerging evidence to suggest that primary SoAD was predictive of poorer outcomes following CBT. However, these results contrast with the conclusion of Lundkvist-Houndoumadi et al. (2014) that there was no significant evidence to suggest that any primary diagnosis was predictive of outcome following CBT for youth anxiety disorders. This is likely due to the availability of trials at the time of Lundkvist-Houndoumadi and colleagues' review, as eight of the trials in the current review (including all six included in the meta-analysis) were published after Lundkvist-Houndoumadi and colleagues' search was conducted. This may reflect changing trends in the reporting of data: amongst trials which met all other criteria for inclusion in this review, only 7\% published prior to 2014 reported an analysis of the relationship between primary diagnosis and recovery, compared with $32 \%$ in those published from 2014 onwards. Furthermore, it highlights the importance of reporting results as a function of primary anxiety diagnosis in trials of CBT for child and adolescent anxiety disorders.

These results have clear clinical and research implications. The finding that only $35 \%$ of young people with primary social anxiety recovered following generic CBT suggests that treating primary SoAD with current generic models of $\mathrm{CBT}$ is unlikely to enable recovery in the majority of cases. 
However, there is a lack of evidence to suggest what approach may improve CBT outcomes for this population. There is evidence of the effectiveness of social skills interventions for SoAD in preadolescent children (Beidel et al., 2000; Beidel et al., 2005). For the treatment of SoAD in adolescents, a recent case series presented promising results using an adapted version of the Clark and Wells (1995) adult disorder-specific model of CBT (Leigh and Clark, 2016). Additionally, an RCT has reported that adolescents with SoAD experienced significantly greater symptom reduction following CBT based on the Clark and Wells (1995) model compared with a generic CBT approach (Ingul et al., 2014). However, a review completed by Oldham-Cooper and Loades (2017) concluded that there was not sufficient evidence that existing disorder-specific CBT was superior to generic CBT for SoAD in youth. In light of the current review's findings, it is important that disorder-specific interventions such as those evaluated by Leigh and Clark (2016) and Ingul et al. (2014) are further evaluated in largescale RCTs.

It is unclear why young people with SoAD experienced poorer outcomes following generic CBT compared with those with other anxiety disorders. One explanation might be that there are specific processes that maintain SoAD, meaning recovery is less likely if these are not specifically addressed in therapy. For example, adult models of SoAD highlight the role of self-focused attention and negative observer-perspective images as key maintaining factors (Hackmann et al., 2000; Wong and Rapee, 2016). In CBT for social anxiety in adults, this is typically addressed through a combination of attention training exercises, behavioural experiments aimed at exploring the impact of self-focused attention, and video feedback to correct negative images (Schreiber et al., 2015; Warnock-Parkes et al., 2017). The inclusion of these treatment components has been shown to be associated with enhanced treatment outcomes (Schreiber et al., 2015; Warnock-Parkes et al., 2017). Several authors have suggested that the Clark and Wells (1995) model of SoAD, including the role of self-focused attention and negative imagery, is applicable to youth (for a review, see Leigh and Clark, 2018). As generic CBT is unlikely to include procedures to address these disorder-specific maintenance factors, this may explain the poor recovery outcomes observed for youth with primary SoAD. Future research would therefore benefit from exploring this by examining changes in disorder-specific maintenance factors during generic CBT for youth with primary SoAD, to better understand barriers to recovery following this treatment.

It was beyond the scope of this review to consider other predictors of outcome, or the interaction between primary diagnosis and other predictors. This is an important question, especially given findings in one of the included trials (Arendt et al., 2016) that youth with primary SoAD were also likely to be older and have higher rates of co-morbid depression. Future research would benefit from further investigating additional factors such as these and their interaction in predicting recovery from anxiety disorders following CBT. It was also not possible to investigate developmental differences in outcome. There is evidence of developmental differences in social anxiety symptoms and presentation between children and adolescents (Rao et al., 2007). Moreover, studies of the applicability of the Clark and Wells (1995) model of SoAD and maintenance processes such as safety behaviours, self-focused attention and social cognitions have largely focused on adolescents rather than children (Hodson et al., 2008; Leigh and Clark, 2018). It is therefore possible that a different pattern of response to disorder-specific versus generic CBT for SoAD will be observed in children compared with adolescents. Future reviews would therefore benefit from comparing outcomes not just between primary diagnoses but also between children and adolescents. Such a review would benefit from also considering outcomes of alternative psychological treatments which have an evidence base for the treatment of SoAD in children, such as social skills interventions (Beidel et al., 2000; Beidel et al., 2005).

This review has a number of strengths. It included trials of CBT across a range of formats, increasing the generalisability of results. All outcomes were based on validated diagnostic 
tools, and from RCTs published in peer-reviewed journals. Whilst these criteria led to the exclusion of at least one trial which reported outcomes consistent with the conclusions of this review from a non-RCT design (Crawley et al., 2008), overall these criteria were beneficial as they ensured that the review's conclusions were based on high-quality evidence. This was supported by the findings of the quality assessment, which revealed a generally low level of bias and good quality research evidence.

This review also has several limitations. The included papers represent a minority of trials of CBT for anxiety in children and adolescents, as 67 were excluded from the current review as they did not present sufficient data on recovery rates relative to primary diagnosis. It is possible that this led to bias in our findings, for example it could be possible that trials finding evidence of a difference in recovery rates between diagnoses were more likely to report these data. However, the symmetrical funnel plot provides evidence to suggest that results were not affected by such publication bias. A further limitation is that study screening and selection was primarily completed by only one researcher. Although this process was completed cautiously and followed clearly specified inclusion and exclusion criteria, and ambiguities were discussed and agreed within the research team, a more rigorous approach would have been for double coding of studies by a second researcher. The present review also only focused on recovery outcomes at post-treatment, and therefore does not reflect different recovery outcomes which may have been observed at longer-term follow up. For example, Thirlwall et al. $(2013,2017)$ highlighted that whilst young people with primary GAD showed similar rates of recovery from post-treatment to 6-month follow-up, recovery rates amongst young people with other primary anxiety diagnosis continued to improve between these points. The conclusions of the current review may therefore not be replicated at longer term follow-up points. Additionally, our focus on recovery from primary diagnosis prevented conclusions regarding symptom improvement or recovery from non-primary anxiety diagnoses. It was also not possible to extract data on recovery rates following control conditions. Therefore, it is not possible to establish whether the differences observed in recovery between those with different primary anxiety diagnoses are specific to CBT or are reflective of a more general pattern of recovery across conditions.

These limitations notwithstanding, this review has produced important findings with clear research and clinical implications. It has shown, from a small number of recent trials, that young people with primary SoAD are significantly less likely to be in remission from this diagnosis following generic CBT at post-treatment compared with young people with other primary anxiety disorders. This demonstrates the importance of reporting recovery rates relative to primary diagnosis in all trials of CBT for youth anxiety, and the urgent need for further research to enhance understanding of SoAD in young people in order to improve the efficacy of treatment for children and adolescents with this diagnosis.

Supplementary material. To view supplementary material for this article, please visit https://doi.org/10.1017/ S135246582000079X

Acknowledgements. The authors thank Gemma Scott (King's College London) for assisting with quality assessment of the trials, and Mariana Travlou (King's College London) for assisting with data extraction. We also gratefully thank all authors of included trials who responded to requests to provide additional data for inclusion in the meta-analysis.

Financial support. Eleanor Leigh is funded by the Wellcome Trust clinical research training fellowship (102176/Z/13/Z). David M. Clark is a Wellcome Trust (WT069777) and NIHR (NF-SI-0512-10132) senior investigator.

Conflicts of interests. The authors have no conflicts of interest with respect to this publication.

Ethics statements. All authors have abided by the Ethical Principles of Psychologists and Code of Conduct as set out by the British Psychological Society and the British Association of Behavioural and Cognitive Psychotherapy. As this was a systematic review and meta-analysis only, ethical review was not required. 


\section{References}

Aderka, I. M., Hofmann, S. G., Nickerson, A., Hermesh, H., Gilboa-Schechtman, E., \& Marom, S. (2012). Functional impairment in social anxiety disorder. Journal of Anxiety Disorders, 26, 393-400.

Arendt, K., Thastum, M., \& Hougaard, E. (2016). Efficacy of a Danish version of the Cool Kids program: a randomized waitlist controlled trial. Acta Psychiatrica Scandinavica, 133, 109-121. doi: http://dx.doi.org/10.1111/acps.12448

Barrett, P. M. (2004). Friends for life - Group leader's manual (Vol. 4). Brisbane: Australian Academic Press.

Barrett, P. M., Dadds, M. R., \& Rapee, R. M. (1996). Family treatment of childhood anxiety: a controlled trial. Journal of Consulting and Clinical Psychology, 64, 333.

Barrett, P. M., Lowry-Webster, H., \& Turner, C. (2000a). FRIENDS program for children: Parents' supplement. Brisbane: Australian Academic Press.

Barrett, P. M., Lowry-Webster, H., \& Turner, C. (2000b). FRIENDS program for children: Group leaders manual. Brisbane: Australian Academic Press.

Barrett, P. M., Lowry-Webster, H., \& Turner, C. (2000c). FRIENDS program for children: Participants workbook. Brisbane: Australian Academic Press.

Barrett, P. M., Lowry-Webster, H., \& Turner, C. (2000d). FRIENDS program for youth: Group leaders manual. Brisbane: Australian Academic Press.

Barrett, P. M., Lowry-Webster, H., \& Turner, C. (2000e). FRIENDS program for youth: Parents' supplement. Brisbane: Australian Academic Press.

Barrett, P. M., Lowry-Webster, H., \& Turner, C. (2000f). FRIENDS program for youth: Participants workbook. Brisbane: Australian Academic Press.

Beidel, D. C., Turner, S. M., \& Morris, T. L. (2000). Behavioral treatment of childhood social phobia. Journal of Consulting and Clinical Psychology, 68, 1072.

Beidel, D. C., Turner, S. M., Young, B., \& Paulson, A. (2005). Social effectiveness therapy for children: three-year follow-up. Journal of Consulting and Clinical Psychology, 73, 721.

Bruce, S. E., Yonkers, K. A., Otto, M. W., Eisen, J. L., Weisberg, R. B., Pagano, M., . . \& Keller, M. B. (2005). Influence of psychiatric comorbidity on recovery and recurrence in generalized anxiety disorder, social phobia, and panic disorder: a 12-year prospective study. American Journal of Psychiatry, 162, 1179-1187.

Cartwright-Hatton, S., Roberts, C., Chitsabesan, P., Fothergill, C., \& Harrington, R. (2004). Systematic review of the efficacy of cognitive behaviour therapies for childhood and adolescent anxiety disorders. British Journal of Clinical Psychology, 43, 421-436. doi:http://dx.doi.org/10.1348/0144665042388928

Clark, D. M., Ehlers, A., Hackmann, A., McManus, F., Fennell, M., Grey, N., . . \& Wild, J. (2006). Cognitive therapy versus exposure and applied relaxation in social phobia: a randomized controlled trial. Journal of Consulting Clinical Psychology, 74, 568.

Clark, D. M., Ehlers, A., McManus, F., Hackmann, A., Fennell, M., Campbell, H., ... \& Louis, B. (2003). Cognitive therapy versus fluoxetine in generalized social phobia: a randomized placebo-controlled trial. Journal of Consulting and Clinical Psychology, 71, 1058.

Clark, D. M., \& Wells, A. (1995). A cognitive model of social phobia. Social Phobia: Diagnosis, Assessment, and Treatment, 41, 00022-3.

Crawley, S. A., Beidas, R. S., Benjamin, C. L., Martin, E., \& Kendall, P. C. (2008). Treating socially phobic youth with CBT: differential outcomes and treatment considerations. Behavioural and Cognitive Psychotherapy, 36, 379-389. doi: http://dx. doi.org/10.1017/S1352465808004542

Creswell, C., Violato, M., Fairbanks, H., White, E., Parkinson, M., Abitabile, G., .. \& Cooper, P. J. (2017). Clinical outcomes and cost-effectiveness of brief guided parent-delivered cognitive behavioural therapy and solution-focused brief therapy for treatment of childhood anxiety disorders: a randomised controlled trial. The Lancet Psychiatry, 4, 529-539. doi: http://dx.doi.org/10.1016/S2215-0366\%2817\%2930149-9

Creswell, C., Waite, P., \& Cooper, P. J. (2014). Assessment and management of anxiety disorders in children and adolescents. Archives of Disease in Childhood, 99, 674-678. doi: 10.1136/archdischild-2013-303768

Creswell, C., Waite, P., \& Hudson, J. (2020). Practitioner review: anxiety disorders in children and young people assessment and treatment. Journal of Child Psychology and Psychiatry.

Ginsburg, G. S., Kendall, P. C., Sakolsky, D., Compton, S. N., Piacentini, J., Albano, A. M., ... \& March, J. (2011). Remission after acute treatment in children and adolescents with anxiety disorders: findings from the CAMS. Journal of Consulting and Clinical Psychology, 79, 806-813. doi: http://dx.doi.org/10.1037/a0025933

Hackmann, A., Clark, D. M., \& McManus, F. (2000). Recurrent images and early memories in social phobia. Behaviour Research and Therapy, 38, 601-610.

Higgins, J. P., Altman, D. G., Gøtzsche, P. C., Jüni, P., Moher, D., Oxman, A. D., . . \& Sterne, J. A. (2011). The Cochrane Collaboration's tool for assessing risk of bias in randomised trials. BMJ, 343, d5928.

Hodson, K. J., McManus, F. V., Clark, D. M., \& Doll, H. (2008). Can Clark and Wells' (1995) cognitive model of social phobia be applied to young people? Behavioural and Cognitive Psychotherapy, 36, 449-461. 
Holland, D., \& Dadds, M. (1995). Diagnostic Interview Schedule for Child, Adolescents and Parents. Brisbane, Australia: Griffith University.

Hudson, J. L., Keers, R., Roberts, S., Coleman, J. R., Breen, G., Arendt, K., . . \& Heiervang, E. R. (2015). Clinical predictors of response to cognitive-behavioral therapy in pediatric anxiety disorders: the Genes for Treatment (GxT) study. Journal of the American Academy of Child \& Adolescent Psychiatry, 54, 454-463.

Hudson, J. L., Krain, A. L., \& Kendall, P. C. (2001). Expanding horizons: adapting manual-based treatments for anxious children with comorbid diagnoses. Cognitive and Behavioral Practice, 8, 338-346. https://doi.org/10.1016/S1077-7229(01) 80007-9

Ingul, J. M., Aune, T., \& Nordahl, H. M. (2014). A randomized controlled trial of individual cognitive therapy, group cognitive behaviour therapy and attentional placebo adolescent social phobia. Psychotherapy and Psychosomatics, 83, 54-61. doi: http://dx.doi.org/10.1159/000354672

James, A. C., James, G., Cowdrey, F. A., Soler, A., \& Choke, A. (2013). Cognitive behavioural therapy for anxiety disorders in children and adolescents. Cochrane Database of Systematic Reviews (6), CD004690. doi: 10.1002/14651858.CD004690.pub3

Kendall, P. (1994). Treating anxiety disorders in children: results of a randomized clinical trial. Journal of Consulting and Clinical Psychology, 62, 100.

Kendall, P. C., \& Hedtke, K. (2006a). Cognitive-behavioral therapy for anxious children: Therapist manual. Ardmore, PA: Workbook Publishing.

Kendall, P. C., \& Hedtke, K. (2006b). The coping cat workbook. Ardmore, PA: Workbook Publishing.

Kendall, P. C., \& Martinsen, K. D. (2008). Mestringskatten - Gruppemanual [Coping Cat -Manual for groups].

Kendall, P. C., Martinsen, K., \& Neumer, S. (2006). Mestringskatten (Coping Cat).

Kerns, C. M., Read, K. L., Klugman, J., \& Kendall, P. C. (2013). Cognitive behavioral therapy for youth with social anxiety: differential short and long-term treatment outcomes. Journal of Anxiety Disorders, 27, 210-215. doi: http://dx.doi.org/10. 1016/j.janxdis.2013.01.009

Kessler, R. C., Chiu, W. T., Demler, O., \& Walters, E. (2005). Prevalence, severity, and comorbidity of 12-month DSM-IV disorders in the National Comorbidity Survey Replication. Archives of General Psychiatry, 62, 617-627.

Knight, A., McLellan, L., Jones, M., \& Hudson, J. (2014). Pre-treatment predictors of outcome in childhood anxiety disorders: a systematic review. Psychopathology Review, 1, 77-129.

Leichsenring, F., Salzer, S., Beutel, M. E., Herpertz, S., Hiller, W., Hoyer, J., . . \& Poehlmann, K. (2013). Psychodynamic therapy and cognitive-behavioral therapy in social anxiety disorder: a multicenter randomized controlled trial. American Journal of Psychiatry, 170, 759-767.

Leigh, E., \& Clark, D. M. (2016). Cognitive therapy for social anxiety disorder in adolescents: a development case series. Behavioural and Cognitive Psychotherapy, 44, 1-17. doi: http://dx.doi.org/10.1017/S1352465815000715

Leigh, E., \& Clark, D. M. (2018). Understanding social anxiety disorder in adolescents and improving treatment outcomes: applying the cognitive model of Clark and Wells (1995). Clinical Child \& Family Psychology Review, 21, 388-414. doi: 10. 1007/s10567-018-0258-5

Lundkvist-Houndoumadi, I., Hougaard, E., \& Thastum, M. (2014). Pre-treatment child and family characteristics as predictors of outcome in cognitive behavioural therapy for youth anxiety disorders. Nordic Journal of Psychiatry, 68 , 524-535. doi: http://dx.doi.org/10.3109/08039488.2014.903295

Lyneham, H. J., McLellan, L. F., Cunningham, M., Wuthrich, V., Schniering, C., Hudson, J.L. et al. (2014). ChilledOut Online Program. Sydney: Centre for Emotional Health, Macquarie University.

McKnight, P. E., \& Kashdan, T. B. (2009). The importance of functional impairment to mental health outcomes: a case for reassessing our goals in depression treatment research. Clinical Psychology Review, 29, 243-259.

Moher, D., Liberati, A., Tetzlaff, J., \& Altman, D. G. (2009). Preferred reporting items for systematic reviews and metaanalyses: the PRISMA statement. Annals of Internal Medicine, 151, 264-269.

Mörtberg, E., Clark, D., Sundin, Ö., \& Åberg Wistedt, A. (2007). Intensive group cognitive treatment and individual cognitive therapy vs. treatment as usual in social phobia: a randomized controlled trial. Acta Psychiatrica Scandinavica, $115,142-154$.

NICE (2013). Social anxiety disorder: recognition, assessment and treatment. Retrieved from: https://www.nice.org.uk/ guidance/cg159/chapter/1-Recommendations\#interventions-for-adults-with-social-anxiety-disorder-2

Nordahl, H. M., Vogel, P. A., Morken, G., Stiles, T. C., Sandvik, P., \& Wells, A. (2016). Paroxetine, cognitive therapy or their combination in the treatment of social anxiety disorder with and without avoidant personality disorder: a randomized clinical trial. Psychotherapy and Psychosomatics, 85, 346-356.

Oldham-Cooper, R., \& Loades, M. (2017). Disorder-specific versus generic cognitive-behavioral treatment of anxiety disorders in children and young people: a systematic narrative review of evidence for the effectiveness of disorderspecific CBT compared with the disorder-generic treatment, Coping Cat. Journal of Child and Adolescent Psychiatric Nursing, 30, 6-17.

Ranta, K., Kaltiala-Heino, R., Rantanen, P., \& Marttunen, M. (2009). Social phobia in Finnish general adolescent population: prevalence, comorbidity, individual and family correlates, and service use. Depression and Anxiety, 26, 528-536. 
Rao, P. A., Beidel, D. C., Turner, S. M., Ammerman, R. T., Crosby, L. E., \& Sallee, F. R. (2007). Social anxiety disorder in childhood and adolescence: descriptive psychopathology. Behaviour Research and Therapy, 45, 1181-1191.

Rapee, R. M., \& Heimberg, R. G. (1997). A cognitive-behavioral model of anxiety in social phobia. Behaviour Research Therapy, 35, 741-756.

Rapee, R. M., Lyneham, H. J., \& Schniering, C. (2006). The cool kids child and adolescent anxiety program - therapist manual. Sydney, NSW: Centre for Emotional Health, Macquarie University.

Reynolds, S., Wilson, C., Austin, J., \& Hooper, L. (2012). Effects of psychotherapy for anxiety in children and adolescents: a meta-analytic review. Clinical Psychology Review, 32, 251-262. doi: http://dx.doi.org/10.1016/j.cpr.2012.01.005

Schreiber, F., Heimlich, C., Schweitzer, C., \& Stangier, U. (2015). Cognitive therapy for social anxiety disorder: the impact of the 'self-focused attention and safety behaviours experiment' on the course of treatment. Behavioural and Cognitive Psychotherapy, 43, 158-166.

Shortt, A. L., Barrett, P. M., \& Fox, T. L. (2001). Evaluating the FRIENDS program: a cognitive-behavioral group treatment for anxious children and their parents. Journal of Clinical Child Psychology, 30, 525-535.

Silk, J. S., Tan, P. Z., Ladouceur, C. D., Meller, S., Siegle, G. J., McMakin, D. L., . . \& Ryan, N. D. (2018). A randomized clinical trial comparing individual cognitive behavioral therapy and child-centered therapy for child anxiety disorders. Journal of Clinical Child and Adolescent Psychology, 47, 542-554. doi: http://dx.doi.org/10.1080/15374416. 2016.1138408

Silverman, W., \& Albano, A. M. (1996). The Anxiety Disorders Interview Schedule for DSM-IV - Child and Parent Versions. San Antonio, TX, USA: Psychological Corporation.

Silverman, W. K., \& Nelles, W. B. (1988). The Anxiety Disorders Interview Schedule for Children. Journal of the American Academy of Child and Adolescent Psychiatry, 27, 772-778.

Spence, S. H., Donovan, C. L., March, S., Kenardy, J. A., \& Hearn, C. S. (2017). Generic versus disorder specific cognitive behavior therapy for social anxiety disorder in youth: a randomized controlled trial using internet delivery. Behaviour Research and Therapy, 90, 41-57. doi: http://dx.doi.org/10.1016/j.brat.2016.12.003

Stangier, U., Heidenreich, T., Peitz, M., Lauterbach, W., \& Clark, D. (2003). Cognitive therapy for social phobia: individual versus group treatment. Behaviour Research and Therapy, 41, 991-1007.

Stangier, U., Schramm, E., Heidenreich, T., Berger, M., \& Clark, D. M. (2011). Cognitive therapy vs interpersonal psychotherapy in social anxiety disorder: a randomized controlled trial. Archives of General Psychiatry, 68, 692-700.

Stein, M. B., Fuetsch, M., Müller, N., Höfler, M., Lieb, R., \& Wittchen, H.-U. (2001). Social anxiety disorder and the risk of depression: a prospective community study of adolescents and young adults. Archives of General Psychiatry, 58, 251-256.

Stjerneklar, S., Hougaard, E., McLellan, L. F., \& Thastum, M. (2019). A randomized controlled trial examining the efficacy of an internet-based cognitive behavioral therapy program for adolescents with anxiety disorders. Plos One, 14, e0222485.

Suveg, C., Jones, A., Davis, M., Jacob, M. L., Morelen, D., Thomassin, K., \& Whitehead, M. (2018). Emotion-focused cognitive-behavioral therapy for youth with anxiety disorders: a randomized trial. Journal of Abnormal Child Psychology, 46, 569-580. doi: http://dx.doi.org/10.1007/s10802-017-0319-0

Thirlwall, K., Cooper, P., \& Creswell, C. (2017). Guided parent-delivered cognitive behavioral therapy for childhood anxiety: predictors of treatment response. Journal of Anxiety Disorders, 45, 43-48. doi: 10.1016/j.janxdis.2016.11.003

Thirlwall, K., Cooper, P. J., Karalus, J., Voysey, M., Willetts, L., \& Creswell, C. (2013). Treatment of child anxiety disorders via guided parent-delivered cognitive behavioural therapy: randomised controlled trial. British Journal of Psychiatry, 203, 436-444. doi: 10.1192/bjp.bp.113.126698

Van Ameringen, M., Mancini, C., \& Farvolden, P. (2003). The impact of anxiety disorders on educational achievement. Journal of Anxiety Disorders, 17, 561-571.

Villabo, M. A., Narayanan, M., Compton, S. N., Kendall, P. C., \& Neumer, S.-P. (2018). Cognitive-behavioral therapy for youth anxiety: an effectiveness evaluation in community practice. Journal of Consulting and Clinical Psychology, 86, 751-764. doi: http://dx.doi.org/10.1037/ccp0000326

Walczak, M., Ollendick, T., Ryan, S., \& Esbjorn, B. H. (2018). Does comorbidity predict poorer treatment outcome in pediatric anxiety disorders? An updated 10-year review. Clinical Psychology Review, 60, 45-61. doi: http://dx.doi.org/ 10.1016/j.cpr.2017.12.005

Warnock-Parkes, E., Wild, J., Stott, R., Grey, N., Ehlers, A., \& Clark, D. M. (2017). Seeing is believing: using video feedback in cognitive therapy for social anxiety disorder. Cognitive and Behavioral Practice, 24, 245-255.

Wergeland, G. J. H., Fjermestad, K. W., Marin, C. E., Bjelland, I., Haugland, B. S. M., Silverman, W. K., ... \& Heiervang, E. R. (2016). Predictors of treatment outcome in an effectiveness trial of cognitive behavioral therapy for children with anxiety disorders. Behaviour Research and Therapy, 76, 1-12. doi: http://dx.doi.org/10.1016/j.brat.2015.11.001

Wergeland, G. J. H., Fjermestad, K. W., Marin, C. E., Haugland, B. S.-M., Bjaastad, J. F., Oeding, K., . . \& Heiervang, E. R. (2014). An effectiveness study of individual vs. group cognitive behavioral therapy for anxiety disorders in youth. Behaviour Research and Therapy, 57, 1-12. doi: http://dx.doi.org/10.1016/j.brat.2014.03.007 
Willetts, L., Creswell, C., Thirlwall, K., \& Parkinson, M. (2016). Overcoming your child's fears and worries: guided parent delivered CBT treatment manual for therapists.

Wong, Q. J., \& Rapee, R. M. (2016). The aetiology and maintenance of social anxiety disorder: a synthesis of complementary theoretical models and formulation of a new integrated model. Journal of Affective Disorders, 203, 84-100.

Yoshinaga, N., Matsuki, S., Niitsu, T., Sato, Y., Tanaka, M., Ibuki, H., . . \& Asano, K. (2016). Cognitive behavioral therapy for patients with social anxiety disorder who remain symptomatic following antidepressant treatment: a randomized, assessor-blinded, controlled trial. Psychotherapy and Psychosomatics, 85, 208-217.

Cite this article: Evans R, Clark DM, and Leigh E (2021). Are young people with primary social anxiety disorder less likely to recover following generic CBT compared to young people with other primary anxiety disorders? A systematic review and meta-analysis. Behavioural and Cognitive Psychotherapy 49, 352-369. https://doi.org/10.1017/S135246582000079X 